\title{
Condylar positions generated by five centric relation recording techniques
}

Adam L. Swenson, Larry J. Oesterle*, W. Craig Shellhart, Sheldon M. Newman and Gerald Minick

*Correspondence: larry.oesterle@ucdenver.edu

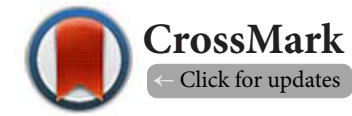

Department of Orthodontics, School of Dental Medicine, University of Colorado, Colorado, USA.

\begin{abstract}
Objective: The method and consistency of finding centric relation $(\mathrm{CR})$ is highly controversial. This study evaluated the relative condylar locations generated by five different CR interocclusal recording techniques.

Materials and methods: Condylar location was measured using the Measures Condylar Displacement (MCD) instrument of the $\mathrm{AD} 2$ articulator on five symptom free subjects between 26-36 years of age. The five CR interocclusal recording techniques studied were the Roth Power Bite, Tongue Tip to Soft Palate, Leaf Gauge, Chin Point Guidance, and Bimanual Manipulation. Five different CR registrations on each patient were made at five time points.
\end{abstract}

Results: Small intra- and inter-technique variations were found in the condylar positions generated by the five CR registration techniques. The Roth Power Bite and Leaf Gauge methods positioned more condyles in an upward and forward location relative to other techniques. The Chin Point Guidance, Tongue Tip to Soft Palate, and Bimanual Manipulation Techniques tended to position condyles slightly more inferior and posterior than other methods.

Conclusions: All methods of CR registration resulted in a very small range of variation indicating a high degree of intra-technique repeatability. However, location within the condylar fossa varied between the different techniques with the Roth Power Bite and Leaf Gauge Techniques positioning condyles slightly more anterior-superior than other techniques studied.

Keywords: Centric relation, adult, dental occlusion, humans, reproducibility of results, temporomandibular joint/physiology, dental articulators

\section{Introduction}

At present, there is no established "gold standard" method of recording patients' centric relation (CR) position [1-3]. Rather, many different techniques are surrounded by open-ended controversy regarding their comparative reproducibility and/ or accuracy or even the necessity of mounting study casts in $C R$ [4]. This lack of evidence can prove frustrating to the $C R$ conscious clinician.

Many $C R$ registration techniques were developed and were categorized in several ways. One difference between techniques was if it was patient-passive or patient-active. Patient-passive techniques require the dentist's assistance and patient-active techniques do not. Another category is the direct interocclusal record where a patient's jaw relationship is recorded with a thermoplastic or a self-hardening recording medium interposed between the maxillary and mandibular teeth as the mandible hinges closed $[5,6]$. Still another classification is the functional $\mathrm{CR}$ recording, which is recorded with the patient performing mandibular functional movements.

These various $C R$ registration techniques were developed to manage the many clinical contingencies that obstruct capturing a repeatable $C R$ registration record. The clinician, their equipment/technique, and the patient each introduce their own complicating variables [7]. Yurkstas and Kapur [8] pointed out other variables such as the pliability of the involved tissues, the temporomandibular joint (TMJ) and its associated physiology, the pressure applied while creating the recording, the technique employed, the recording material, the skill of the practitioner, the health and cooperation of the subject, and subject posture. Muscle action was examined by Lundeen [9] 
who found the natural pull of masticatory muscles to be superior and anterior. The direction of pull can be effected by body position as found by Campos et al., [10] who reported a significant difference in condylar position when interocclusal $C R$ records were taken in supine and upright position. It is not surprising then, that a repeatable CR interocclusal record is difficult to obtain.

Several past studies evaluated the repeatability of different $C R$ interocclusal registration techniques. The Bimanual Manipulation Technique was touted as highly repeatable, but also the most technique sensitive $[11,12]$. The Roth Power Bite Technique was found to be repeatable, but was criticized as not physiologic $[2,13]$. Other techniques of recording $C R$ such as Chin Point Guidance, Swallowing, and Tongue Tip to Soft Palate have produced more variable results $[10,11,14]$. A study determining the relative condylar position with different $C R$ recording techniques may help the clinician determine the best technique to use.

The purpose of this investigation was to analyze the relative condylar locations generated by five different $C R$ registration techniques as well as intra-technique repeatability.

\section{Materials and methods}

The sample included four men and one woman from the University of Colorado Orthodontic Clinic patient [1] and resident [4] base. The subjects were from 26 to 36 years of age and met the following inclusion criteria: [1] not undergoing orthodontic treatment [2]; absence of temporomandibular joint signs and symptoms [3]; a complete dentition excluding the third molars; and [4] in good health. The rights of all subjects were protected and the study was approved by the Colorado Multiple Institution Review Board. Written informed consent was obtained from all subjects.

One operator (AS) performed all of the clinical and laboratory procedures. A facebow record of all subjects was made (AD2 Anatomic Facebow, Riverside, CA, USA) using a tripod of compound impression material (Bite Tab, Panodent, Colton, CA, USA) on the bite fork. Polyvinyl siloxane (PVS) impressions (VP Mix HP, Henry Schein, Melville, NY) of the maxillary and mandibular dental arches were made using a custom tray and poured in die stone (Jade Stone, Whip Mix, Louisville, Kentucky). Maxillary casts were then mounted (Mounting Stone, Whip Mix, Louisville, Kentucky) on a semi-adjustable articulator (AD2 Articulator, Riverside, CA, USA). An interocclusal centric occlusion (CO) record was made on each patient using polyvinyl siloxane bite registration material (BluMousse, Parkell, Farmingdale, N.Y.), was trimmed to include only cusp tips and used to mount the mandibular cast in centric occlusion, which was the constant reference point that the five $C R$ interocclusal registrations were compared to.

Each of the five $C R$ registration techniques was performed on each patient at five different time points. The sequences and timing (morning or afternoon) of the $\mathrm{CR}$ registration techniques at each time point were randomized before the study began. Each time point occurred at least one week after the previous recording and all techniques were performed in a supine subject position.

\section{Roth power centric bite}

The Roth Power Bite Technique was performed using a wax wafer (Bite Registration Sheet Wax, Almore Int. Inc., Portland, Oregon) that was heated in a warm water bath. After placing the heated wax in the subject's mouth, the subject was instructed to put their tongue to the roof of their mouth and relax their lower jaw while the operator, holding the mandibular symphysis, guided the lower incisors into the wax. Next, the subject was instructed to close their posterior teeth into the wax. When the cusp tips of the lower posterior teeth had impressed the wax, the subject was instructed to stop. After removal from the subject's mouth, the anterior portion of the wax wafer was hardened in an ice water bath followed by flame heating the posterior portions of the wax wafer. The wax was returned to the mouth and the subject instructed to "bite and hold" into the hard anterior stop, allowing the posterior teeth to embed in the soft posterior wax. The posterior wax was cooled with air from an air/water syringe and removed. After it had cooled, the bite was checked intra-orally for accuracy.

\section{Tongue tip to soft palate}

To create an interocclusal record using the Tongue Tip to Soft Palate Technique, the subject was instructed to touch their tongue as posteriorly as possible to their soft palate while slowly closing into a PVS registration material. The material was allowed to harden and removed from the subject's mouth.

\section{Chin point guidance}

To perform the Chin Point Guidance Technique, the operator grasped the chin (mandibular symphysis) and guided the subject's mandible into the PVS registration material. The registration material was then allowed to set before removing it from the subject's mouth.

\section{Bimanual manipulation}

The Bimanual Manipulation Technique was performed by placing both of the operator's hands under the subject's mandible. Slight superior pressure was applied at the gonial angle and inferior pressure at the mandibular symphysis, guiding the mandible into PVS registration material. This registration material was allowed to harden and removed from the subject's mouth.

\section{Leaf gauge}

To obtain an interocclusal record using the Leaf Gauge Technique, a soft plastic leaf gauge was placed between the subject's maxillary and mandibular incisors such that the number of leaves provided sufficient vertical dimension to just disocclude the posterior teeth. This was maintained for 5 minutes with subjects sitting upright. The subject was then placed in a 
supine position, the leaf gauge removed without allowing any occlusal contact, and the PVS registration material applied to the occlusal surfaces of the mandibular teeth. The leaf gauge was then replaced and the subject instructed to close into the registration material in the previous position, using the leaf gauge as an anterior stop. The registration material was allowed to set and then removed the patient's mouth.

After the $5 \mathrm{CR}$ registrations were completed, the registrations made with the PVS material were trimmed such that only cusp tip imprints were present on both the superior and inferior surfaces of the bite registration. All the condylar measurements were made within 24 hours of obtaining the interocclusal $C R$ registration. The MCD Instrument (AD2, Measures Condylar Displacement, Riverside, CA, USA) was used to measure the condylar location determined by each $\mathrm{CR}$ registration relative to the $\mathrm{CO}$ position (graph origin).

Measurements were then made along both the $\mathrm{X}$ and $\mathrm{Y}$ axis from the dot created in CR on the MCD graph to the graph's origin using digital photographs magnified and calibrated in Microsoft Paint. The photograph was magnified in Microsoft Paint and the pixels corresponding to both the $X$ and $Y$ coordinates of the $\mathrm{CR}$ position, the calibration points (for correction for magnification), and the graph origin were recorded. The following calculation was done:

$$
\begin{aligned}
& C 1 X=x \text { axis of calibration point } 1 \\
& C 2 X=x \text { axis of calibration point } 2 \\
& C 1 Y=y \text { axis of calibration point } 1 \\
& C 2 Y=y \text { axis of calibration point } 2 \\
& D X=x \text { axis of data point } \\
& D Y=y \text { axis of data point } \\
& O X=x \text { axis of origin } \\
& O Y=y \text { axis of origin }
\end{aligned}
$$

$1 \mathrm{~mm}=$ Distance along $x$ and $y$ axis between calibration point 1 and 2 as determined by the Cartesian coordinate system.

$$
\begin{aligned}
& A=\text { Distance in } m m \text { of the } C R \text { position from } C O \text { position } \\
& \text { (graph origin) on } x \text { axis) } \\
& B=\text { Distance in } m m \text { of the } C R \text { position from } C O \text { position } \\
& \text { (graph origin) on } y \text { axis) } \\
& \text { Then: } \\
& \quad A=(D X-O X) /(C 1 X-C 2 X) \\
& B=(D Y-O Y) /(C 1 Y-C 2 Y)
\end{aligned}
$$

The right and left condylar positions were compared using paired $\mathrm{T}$ tests. For both right and left condylar positions, means and standard deviations were calculated for condylar locations in the vertical and anterior-posterior dimensions. An ANOVA and Student Newman Keuls Analysis were used to determine statistically significant differences.

\section{Results}

The results are presented in Tables 1-3 and Figure 1. Tables 1 and 2 are the results for the condylar displacements of left and right condyles individually. The right and left condylar positions were significantly different in several respects (Table 3 ).
In the anterior-posterior dimension, the Roth Power Bite, the Leaf Gauge and the Tongue Tip to Palate techniques all positioned the subjects' left condyles significantly more anterior than other techniques. In all subjects, condylar position resulting from the Roth Power Bite and Leaf Gauge Techniques were not significantly different from each other. In subjects $A, E, K$ and $W$, there were no significant differences in the anteriorposterior dimension for right condyles between methods.

In the vertical dimension, all subjects' right condyles were positioned significantly more superior with the Roth Power Bite and Leaf Gauge Technique than with any other technique. Left condyles were positioned further superior by the Roth Power Bite in Subjects $A$ and $E$ but were not significantly different than the Leaf Gauge Technique for Subject H. There were no significant differences in the vertical dimension between any of the five methods for Subjects K or W.

The scatter grams provide a visual presentation of the combined right and left condylar positions. The ellipse encompasses all points to provide a general location of the condylar position and shows the small degree of variation in CR condylar position relative to the $\mathrm{CR}$ position (graph origin) (Figure 1). All CR condylar positions fall within $2 \mathrm{~mm}$ of the $\mathrm{CO}$ position in all dimensions with the exception of the superior direction. Superiorly, all data points fall within three millimeters. The small range of variation in condylar location is confirmed by the coefficients of variance (Table 3). For both right and left condyles, there was a higher degree of variation in the anterior-posterior position than in the vertical position (Table 3). For right and left condyles, the Roth Power Bite Technique had the highest coefficients of variance (or greatest variability) of all methods in the anterior-posterior position and the least variability in the vertical position. For both right and left condyles, the Chin Point Guidance Technique had the highest variation in the vertical dimension (Table 3 ).

\section{Discussion}

Determining whether a particular $\mathrm{CR}$ registration technique resulted in condylar positions in keeping with the definition $C R$ is difficult to validate. The current centric relation definition claims to be both a reference point of mandibular location relative to the maxilla and the most musculoskeletally stable position where the condylar head is in a superior and anterior position in the articular fossae [15]. Ensuring that a CR registration produced condylar locations compliant with this definition requires the use of computed tomography or magnetic resonance imagining (MRI) due to its physiologic nature, which is impractical for routine treatment [16].

More practical is the assessment of a CR registration technique's repeatability. A technique which is repeatable may be most useful in evaluating treatment outcomes in a clinical setting. Yet, the complex anatomy of the TMJ makes this analysis difficult as well. This joint is an atypical diarthrodial joint capable of simultaneous rotational and translational movements [15]. Further, expected anatomical asymmetry requires 
Table 1. Left side condylar positions arranged by subject and technique. Means and standard deviations with coefficient of variance reported in the anterior-posterior and vertical dimensions. Statistical significance reported where "a" is significantly different from " $b$ " at $\mathbf{p} \geq \mathbf{0 . 0 5}$.

\begin{tabular}{|c|c|c|c|c|c|c|c|c|c|}
\hline \multirow[t]{2}{*}{ Group } & \multirow[t]{2}{*}{ Method } & \multirow[t]{2}{*}{ Subject } & \multirow[t]{2}{*}{$\mathbf{N}$} & \multicolumn{3}{|c|}{ Anterior/Posterior plane } & \multicolumn{3}{|c|}{ Vertical plane } \\
\hline & & & & \begin{tabular}{|l} 
Mean \pm Std Dev. \\
$(\mathrm{Mm})$
\end{tabular} & Stat Diff & $\begin{array}{l}\text { Coefficient } \\
\text { of variance }\end{array}$ & $\begin{array}{l}\text { Mean } \pm \text { Std Dev. } \\
(\mathrm{Mm})\end{array}$ & Stat Diff & $\begin{array}{l}\text { Coefficient } \\
\text { of variance }\end{array}$ \\
\hline 1 & Roth & A & 5 & $-0.037 \pm 0.36$ & $\mathrm{a}$ & $-97.91 \%$ & $1.33 \pm 0.57$ & $\mathrm{a}$ & $42.69 \%$ \\
\hline 2 & Leaf & $\mathrm{A}$ & 5 & $-0.15 \pm 0.38$ & $\mathrm{a}$ & $-259.56 \%$ & $0.25 \pm 0.47$ & $\mathrm{~b}$ & $188.08 \%$ \\
\hline 3 & Tongue & A & 5 & $-0.34 \pm 0.34$ & $a, b$ & $-101.45 \%$ & $0.14 \pm 0.33$ & $\mathrm{~b}$ & $235.89 \%$ \\
\hline 4 & Bimanual & A & 5 & $-0.59 \pm 0.15$ & $\mathrm{~b}$ & $-25.99 \%$ & $-0.12 \pm 0.10$ & $\mathrm{~b}$ & $-79.07 \%$ \\
\hline 5 & Chin & A & 5 & $-0.43 \pm 0.14$ & $\mathrm{~b}$ & $-94.76 \%$ & $0.19 \pm 0.35$ & $\mathrm{~b}$ & $188.53 \%$ \\
\hline 6 & Roth & $\mathrm{E}$ & 5 & $0.34 \pm 0.16$ & $\mathrm{a}$ & $47.25 \%$ & $2.05 \pm 0.34$ & a & $16.33 \%$ \\
\hline 7 & Leaf & $\mathrm{E}$ & 5 & $-0.28 \pm 0.22$ & $\mathrm{a}$ & $-78.39 \%$ & $1.18 \pm 0.50$ & $\mathrm{~b}$ & $42.33 \%$ \\
\hline 8 & Tongue & $\mathrm{E}$ & 5 & $-0.19 \pm 0.28$ & $a, b$ & $-143.96 \%$ & $0.73 \pm 0.31$ & $\mathrm{~b}$ & $43.16 \%$ \\
\hline 9 & Bimanual & $\mathrm{E}$ & 5 & $-0.33 \pm 0.24$ & $\mathrm{~b}$ & $-71.42 \%$ & $0.66 \pm 0.13$ & $\mathrm{~b}$ & $19.20 \%$ \\
\hline 10 & Chin & $\mathrm{E}$ & 5 & $-0.35 \pm 0.25$ & $\mathrm{~b}$ & $-71.90 \%$ & $0.57 \pm 0.40$ & $\mathrm{~b}$ & $70.51 \%$ \\
\hline 11 & Roth & $\mathrm{H}$ & 5 & $-0.03 \pm 0.40$ & $\mathrm{a}$ & $-1235.67 \%$ & $0.89 \pm 0.23$ & $a, b$ & $26.35 \%$ \\
\hline 12 & Leaf & $\mathrm{H}$ & 5 & $-0.06 \pm 0.47$ & $\mathrm{a}$ & $-823.45 \%$ & $1.03 \pm 0.28$ & a & $26.83 \%$ \\
\hline 13 & Tongue & $\mathrm{H}$ & 5 & $-0.36 \pm 0.19$ & $a, b$ & $-52.86 \%$ & $0.37 \pm 0.30$ & $\mathrm{~b}$ & $80.02 \%$ \\
\hline 14 & Bimanual & $\mathrm{H}$ & 5 & $-0.36 \pm 0.16$ & $\mathrm{~b}$ & $-46.30 \%$ & $0.35 \pm 0.24$ & $\mathrm{~b}$ & $68.27 \%$ \\
\hline 15 & Chin & $\mathrm{H}$ & 5 & $-0.59 \pm 0.22$ & $\mathrm{~b}$ & $-38.13 \%$ & $0.45 \pm 0.33$ & $\mathrm{~b}$ & $71.90 \%$ \\
\hline 16 & Roth & $\mathrm{K}$ & 5 & $0.65 \pm 0.66$ & $\mathrm{a}$ & $101.47 \%$ & $0.67 \pm 0.47$ & a & $69.64 \%$ \\
\hline 17 & Leaf & $\mathrm{K}$ & 5 & $0.38 \pm 0.57$ & $\mathrm{a}$ & $152.86 \%$ & $0.63 \pm 0.35$ & a & $55.31 \%$ \\
\hline 18 & Tongue & $\mathrm{K}$ & 5 & $0.49 \pm 0.61$ & $a, b$ & $122.75 \%$ & $0.65 \pm 0.65$ & a & $100.64 \%$ \\
\hline 19 & Bimanual & $\mathrm{K}$ & 5 & $0.23 \pm 0.31$ & $\mathrm{~b}$ & $133.43 \%$ & $0.41 \pm 0.38$ & a & $92.97 \%$ \\
\hline 20 & Chin & $\mathrm{K}$ & 5 & $-0.08 \pm 0.24$ & $\mathrm{~b}$ & $-308.52 \%$ & $0.07 \pm 0.37$ & a & $527.74 \%$ \\
\hline 21 & Roth & $\mathrm{W}$ & 5 & $-0.72 \pm 0.37$ & a & $-50.92 \%$ & $1.24 \pm 0.51$ & $\mathrm{a}$ & $41.30 \%$ \\
\hline 22 & Leaf & $\mathrm{W}$ & 5 & $-0.40 \pm 0.41$ & $\mathrm{a}$ & $-103.04 \%$ & $1.26 \pm 0.44$ & $\mathrm{a}$ & $35.14 \%$ \\
\hline 23 & Tongue & $\mathrm{W}$ & 5 & $-0.62 \pm 0.15$ & $a, b$ & $-24.37 \%$ & $0.73 \pm 0.24$ & a & $32.81 \%$ \\
\hline 24 & Bimanual & $\mathrm{W}$ & 5 & $-0.88 \pm 0.32$ & $\mathrm{~b}$ & $-36.17 \%$ & $0.64 \pm 0.24$ & a & $38.02 \%$ \\
\hline 25 & Chin & $\mathrm{W}$ & 5 & $-0.63 \pm 0.40$ & $\mathrm{~b}$ & $-64.16 \%$ & $0.88 \pm 0.38$ & a & $43.69 \%$ \\
\hline Total & & & 125 & & & & & & \\
\hline
\end{tabular}

that right and left condyles be evaluated independently [16].

To analyze the repeatability of the different interocclusal record techniques, the graphs from the MCD instrument were overlaid (Figure 1). This gave a side by side, visual comparison of the condylar positions generated by the different techniques on a single Cartesian coordinate system. The MCD graph's origin from the casts mounted in CO served as the reference point to compare the different techniques.

In our study the Roth Power Bite and Leaf Gauge Techniques generally positioned condyles in a more superior-anterior position than the other techniques, similar to the findings of Wood and Elliot [12]. They found that condyles moved inferiorly and posteriorly as the occlusion moved from a Roth
Power Bite $\mathrm{CR}$ position to $\mathrm{CO}$, which is similar to our findings. In our study the condylar positions generated by the Roth Power Bite and the Leaf Gauge Techniques were, generally, not significantly different. Our finding did not agree with the results of Williamson [17], who found that the Leaf Gauge Technique positioned condyles in a more posterior location than the Roth Power Bite Technique. The similarities in the condylar positions from the Roth Power Bite and Leaf Gauge Techniques are probably because both are functional recordings where the elevator muscles seat the condyles by using an anterior stop [9,18-20].

Correspondingly, all techniques we evaluated that did not use an anterior stop produced similar condylar locations. In all 
Swenson et al. Oral Biology and Dentistry 2014,

http://www.hoajonline.com/journals/pdf/2053-5775-2-8.pdf

doi: $10.7243 / 2053-5775-2-8$

Table 2. Right side condylar positions arranged by subject technique. Means and standard deviations with coefficients of variance reported in the anterior-posterior and vertical dimensions. Statistical significance reported where "a" is significantly different from " $b$ " at $p \geq 0.05$.

\begin{tabular}{|c|c|c|c|c|c|c|c|c|c|}
\hline \multirow[t]{2}{*}{ Group } & \multirow[t]{2}{*}{ Method } & \multirow[t]{2}{*}{ Subject } & \multirow[t]{2}{*}{$\mathbf{N}$} & \multicolumn{3}{|c|}{ Anterior/Posterior plane } & \multicolumn{3}{|c|}{ Vertical plane } \\
\hline & & & & $\begin{array}{l}\text { Mean } \pm \text { Std Dev. } \\
(\mathrm{Mm})\end{array}$ & Stat Diff & $\begin{array}{l}\text { Coefficient of } \\
\text { variance }\end{array}$ & $\begin{array}{l}\text { Mean } \pm \text { Std Dev. } \\
(\mathrm{Mm})\end{array}$ & Stat Diff & $\begin{array}{l}\text { Coefficient of } \\
\text { variance }\end{array}$ \\
\hline 1 & Roth & A & 5 & $-0.50 \pm 0.47$ & a & $-93.98 \%$ & $1.41 \pm 0.48$ & $\mathrm{a}$ & $34.27 \%$ \\
\hline 2 & Leaf & A & 5 & $-0.33 \pm 0.22$ & $\mathrm{a}$ & $-66.57 \%$ & $0.79 \pm 0.39$ & $\mathrm{~b}$ & $49.60 \%$ \\
\hline 3 & Tongue & A & 5 & $-0.15 \pm 0.37$ & $\mathrm{a}$ & $-241.31 \%$ & $0.62 \pm 0.35$ & c & $55.69 \%$ \\
\hline 4 & Bimanual & A & 5 & $-0.23 \pm 0.31$ & a & $-136.62 \%$ & $041 \pm 0.16$ & c & $37.85 \%$ \\
\hline 5 & Chin & $\mathrm{A}$ & 5 & $-0.23 \pm 0.28$ & $\mathrm{a}$ & $-120.65 \%$ & $0.61 \pm 0.25$ & c & $40.40 \%$ \\
\hline 6 & Roth & $\mathrm{E}$ & 5 & $0.29 \pm 0.54$ & $\mathrm{a}$ & $184.65 \%$ & $1.62 \pm 0.25$ & $\mathrm{a}$ & $15.60 \%$ \\
\hline 7 & Leaf & E & 5 & $-0.33 \pm 0.50$ & $\mathrm{a}$ & $-151.40 \%$ & $1.12 \pm 0.43$ & $\mathrm{~b}$ & $38.75 \%$ \\
\hline 8 & Tongue & E & 5 & $-0.22 \pm 0.14$ & $\mathrm{a}$ & $-64.62 \%$ & $0.92 \pm 0.28$ & c & $30.70 \%$ \\
\hline 9 & Bimanual & $\mathrm{E}$ & 5 & $-0.23 \pm 0.17$ & $\mathrm{a}$ & $-72.61 \%$ & $0.79 \pm 0.26$ & c & $32.34 \%$ \\
\hline 10 & Chin & $\mathrm{E}$ & 5 & $-048 \pm 0.27$ & $\mathrm{a}$ & $-55.63 \%$ & $0.85 \pm 0.33$ & c & $38.48 \%$ \\
\hline 11 & Roth & $\mathrm{H}$ & 5 & $0.71 \pm 0.26$ & $\mathrm{a}$ & $36.63 \%$ & $1.35 \pm 0.30$ & $\mathrm{a}$ & $22.02 \%$ \\
\hline 12 & Leaf & $\mathrm{H}$ & 5 & $0.43 \pm 0.13$ & $a b$ & $30.88 \%$ & $1.28 \pm 0.42$ & $\mathrm{~b}$ & $32.73 \%$ \\
\hline 13 & Tongue & $\mathrm{H}$ & 5 & $0.07 \pm 0.28$ & $\mathrm{~b}$ & $418.59 \%$ & $0.83 \pm 0.15$ & c & $17.84 \%$ \\
\hline 14 & Bimanual & $\mathrm{H}$ & 5 & $0.19 \pm 0.31$ & $\mathrm{ab}$ & $163.96 \%$ & $0.80 \pm 0.41$ & c & $51.61 \%$ \\
\hline 15 & Chin & $\mathrm{H}$ & 5 & $0.00 \pm 0.28$ & $\mathrm{~b}$ & undefined & $0.77 \pm 0.31$ & c & $39.76 \%$ \\
\hline 16 & Roth & $\mathrm{K}$ & 5 & $0.03 \pm 0.39$ & $\mathrm{a}$ & $1253.31 \%$ & $1.29 \pm 0.37$ & $\mathrm{a}$ & $28.83 \%$ \\
\hline 17 & Leaf & K & 5 & $0.22 \pm 0.58$ & $\mathrm{a}$ & $261.05 \%$ & $1.39 \pm 0.58$ & $\mathrm{~b}$ & $41.67 \%$ \\
\hline 18 & Tongue & $\mathrm{K}$ & 5 & $0.25 \pm 0.55$ & $\mathrm{a}$ & $218.11 \%$ & $1.44 \pm 0.50$ & c & $34.98 \%$ \\
\hline 19 & Bimanual & $\mathrm{K}$ & 5 & $0.22 \pm 0.52$ & $\mathrm{a}$ & $232.65 \%$ & $1.27 \pm 0.54$ & c & $42.51 \%$ \\
\hline 20 & Chin & $\mathrm{K}$ & 5 & $-0.37 \pm 0.37$ & $\mathrm{a}$ & $-99.13 \%$ & $0.64 \pm 0.54$ & c & $83.76 \%$ \\
\hline 21 & Roth & W & 5 & $-0.46 \pm 0.34$ & $\mathrm{a}$ & $-74.50 \%$ & $2.38 \pm 0.27$ & a & $11.38 \%$ \\
\hline 22 & Leaf & W & 5 & $-0.22 \pm 0.45$ & $\mathrm{a}$ & $-204.61 \%$ & $2.28 \pm 0.63$ & $\mathrm{~b}$ & $27.41 \%$ \\
\hline 23 & Tongue & W & 5 & $-0.74 \pm 0.26$ & $\mathrm{a}$ & $-35.46 \%$ & $1.80 \pm 0.24$ & c & $13.09 \%$ \\
\hline 24 & Bimanual & W & 5 & $-0.57 \pm 0.18$ & $\mathrm{a}$ & $-31.94 \%$ & $1.53 \pm 0.21$ & c & $13.84 \%$ \\
\hline 25 & Chin & W & 5 & $-0.54 \pm 0.38$ & $\mathrm{a}$ & $-70.09 \%$ & $1.86 \pm 0.34$ & c & $18.39 \%$ \\
\hline Total & & & 125 & & & & & & \\
\hline
\end{tabular}

condyles and dimensions, the Bimanual Manipulation, Tongue Tip to the Palate, and Chin Point Guidance Techniques produced condylar positions that were not significantly different. These techniques positioned the condyles more inferiorly and posteriorly relative to the condylar positions obtained from the Roth Power Bite and Leaf Gauge Techniques. Alverez et al., [21] also found no difference between condylar locations produced by the Chin Point Guidance and Bimanual Manipulation Techniques in the anterior-posterior dimension. Kantor et al., [11] likewise, found that the Chin Point Guidance and Bimanual Manipulation Techniques created the most similar mandibular displacement when compared with a swallowing technique and Chin Point Guidance with an anterior jig.
Techniques that do not use the subjects' functional movement against an anterior stop produce similar condylar positions [16].

All interocclusal record techniques studied were generally found to be repeatable with a low range of variation as seen on composite graphs (Figure 1). There is no established range of acceptable condylar position variability for CR interocclusal records. For this reason, repeatability data can only be compared between techniques and not to any previously established standard [16]. For all techniques and subjects, CR condylar positions fell within $2 \mathrm{~mm}$ from the $\mathrm{CO}$ position anterior-posteriorly and $3 \mathrm{~mm}$ vertically.

Variation was found within and between patients for all techniques. The coefficients of variance of the Roth Power Bite 


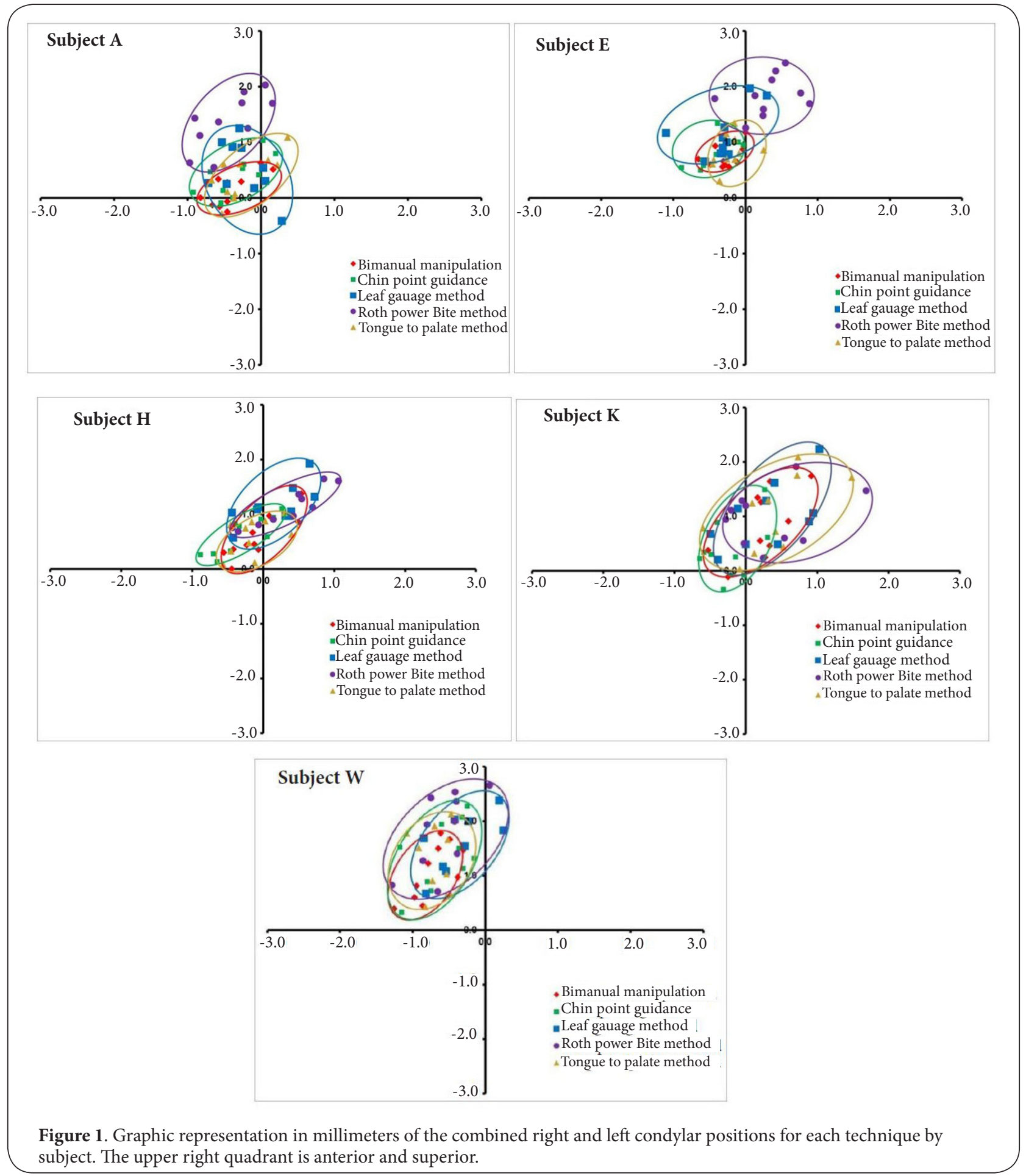

Technique were the lowest (smallest variation) in the vertical dimension for right and left condyles, but were the highest (largest variation) in the anterior-posterior dimension (Table 3). Our findings are similar to those of Schmitt et al., [13] who found the Roth Power Bite Technique to be repeatable. Possible sources of variation in the anterior-posterior dimension are variation in subjects' occlusal forces or distortion of the wax records. The Chin Point Guidance Technique had the highest coefficient of variance in the vertical dimension for right and left condyles. A possible source of this variation was mandibular movement while the PVS bite registration material was setting. Our results are similar to those of Kantor 
Table 3. Column 3 is the results of a paired t test comparing significance of right and left condylar positions by dimension at $p \geq 0.05$. Columns 4 and 5 are the average coefficients of variance by technique and dimension (the higher the percentage, the greater the variation).

\begin{tabular}{|c|c|c|c|c|}
\hline Method & Dimension & $\begin{array}{l}\text { Statistical significance } \\
\text { of right vs. left } \\
\text { condylar data }\end{array}$ & $\begin{array}{l}\text { Left condyle } \\
\text { coefficients of } \\
\text { variance }\end{array}$ & $\begin{array}{l}\text { Right condyle } \\
\text { coefficients of } \\
\text { variance }\end{array}$ \\
\hline \multirow{2}{*}{$\begin{array}{l}\text { Bimanual } \\
\text { manipulation }\end{array}$} & Vertical & Different & $59.51 \%$ & $35.63 \%$ \\
\hline & Anterior/Posterior & Different & $62.66 \%$ & $127.56 \%$ \\
\hline \multirow{2}{*}{$\begin{array}{l}\text { Chin point } \\
\text { guidance }\end{array}$} & Vertical & Not different & $180.47 \%$ & $44.16 \%$ \\
\hline & Anterior/Posterior & Different & $115.49 \%$ & $58.56 \%$ \\
\hline \multirow{2}{*}{ Leaf gauge } & Vertical & Not different & $69.54 \%$ & $38.03 \%$ \\
\hline & Anterior/Posterior & Different & $283.46 \%$ & $142.90 \%$ \\
\hline \multirow{2}{*}{$\begin{array}{l}\text { Roth power } \\
\text { bite }\end{array}$} & Vertical & Not different & $39.26 \%$ & $22.42 \%$ \\
\hline & Anterior/Posterior & Different & $306.64 \%$ & $328.61 \%$ \\
\hline \multirow{2}{*}{$\begin{array}{l}\text { Tongue tip to } \\
\text { palate }\end{array}$} & Vertical & Not different & $98.50 \%$ & $30.46 \%$ \\
\hline & Anterior/Posterior & Different & $89.08 \%$ & $195.62 \%$ \\
\hline
\end{tabular}

et al., [11] who found the Chin Point Guidance Technique was less repeatable than Bimanual Manipulation.

In summary, all of the $C R$ registration methods examined in our study had a small range of variation, supporting the view that any of these techniques may be regarded as repeatable (Figure 1). However, there were subtle differences in positioning of the condyle in $C R$, with those techniques that require biting against an incisal stop (Roth and Leaf Gauge), positioning the condyle more anterior and superior in the glenoid fossa. This finding, to greater or lesser degrees, were found in many studies [22-24]. While the small range of variation found in our study makes it difficult to identify trends in the condylar positions created by these $C R$ registration techniques, some patterns did emerge.

\section{Conclusions}

All CR registration methods evaluated were repeatable as evidenced by the small range of condylar positions. The Roth Power Bite and Leaf Gauge Techniques positioned condyles slightly more anterior and superior than the other techniques.

\section{Competing interests}

The authors declare that they have no competing interests.

\section{Authors' contributions}

\begin{tabular}{|l|c|c|c|c|c|}
\hline Authors' contributions & ALS & LJO & WCS & SMN & GM \\
\hline Research concept and design & $\checkmark$ & $\checkmark$ & -- & $\checkmark$ & -- \\
\hline Collection and/or assembly of data & $\checkmark$ & $\checkmark$ & -- & $\checkmark$ & -- \\
\hline Data analysis and interpretation & $\checkmark$ & $\checkmark$ & -- & $\checkmark$ & -- \\
\hline Writing the article & $\checkmark$ & $\checkmark$ & -- & -- & -- \\
\hline Critical revision of the article & $\checkmark$ & $\checkmark$ & $\checkmark$ & $\checkmark$ & $\checkmark$ \\
\hline Final approval of article & $\checkmark$ & $\checkmark$ & $\checkmark$ & $\checkmark$ & $\checkmark$ \\
\hline Statistical analysis & $\checkmark$ & -- & -- & $\checkmark$ & -- \\
\hline
\end{tabular}

\section{Acknowledgement}

We would like to thank the patients/residents who participated in the project.

\section{Publication history}

Senior Editor: Paul Batchelor, University College London, UK. EIC: Thimios A. Mitsiadis, University of Zurich, Switzerland. Received: 14-Jul-2014 Final Revised: 19-Sep-2014 Accepted: 28-Sep-2014 Published: 02-Oct-2014

\section{References}

1. Hughes GA and Regli CP. What is centric relation? J Prosthet Dent. 1961; 11:16-22.

2. Utt TW, Meyers CE, Jr., Wierzba TF and Hondrum SO. A threedimensional comparison of condylar position changes between centric relation and centric occlusion using the mandibular position indicator. Am J Orthod Dentofacial Orthop. 1995; 107:298-308. I Article I PubMed

3. Utz KH, Muller F, Luckerath W, Fuss E and Koeck B. Accuracy of check-bite registration and centric condylar position. J Oral Rehabil. 2002; 29:45866. I Article I PubMed

4. Rinchuse DJ and Kandasamy S. Myths of orthodontic gnathology. Am J Orthod Dentofacial Orthop. 2009; 136:322-30. | Article | PubMed

5. Smith HF, Jr. A comparison of empirical centric relation records with location of terminal hinge axis and apex of the gothic arch tracing. $J$ Prosthet Dent. 1975; 33:511-20. | Article | PubMed

6. Myers ML. Centric relation records-historical review. J Prosthet Dent 1982; 47:141-5. | Article | PubMed

7. Kingery $\mathrm{RH}$. A review of some of the problems associated with centric relation. J Prosthet Dent. 1952; 2:307-319. | Article

8. Yurkstas AA and Kapur KK. Factors influencing centric relation records in edentulous mouths. 1964. J Prosthet Dent. 2005; 93:305-10. | Article | PubMed

9. Lundeen HC. Centric relation records: the effect of muscle action. J Prosthet Dent. 1974; 31:244-53. | Article | PubMed

10. Campos AA, Nathanson D and Rose L. Reproducibility and condylar position of a physiologic maxillomandibular centric relation in upright and supine body position. J Prosthet Dent. 1996; 76:282-7. | Article | PubMed

11. Kantor ME, Silverman SI and Garfinkel L. Centric-relation recording techniques--a comparative investigation. J Prosthet Dent. 1972; 28:593600. | Article | PubMed 
12. Wood DP and Elliott RW. Reproducibility of the centric relation bite registration technique. Angle Orthod. 1994; 64:211-20. | Article | PubMed

13. Schmitt ME, Kulbersh R, Freeland T, Bever K and Pink FE. Reproducibility of the Roth power centric in determining centric relation. Semin Orthod. 2003; 9:102-108. | Article

14. Simon RL and Nicholls JI. Variability of passively recorded centric relation. J Prosthet Dent. 1980; 44:21-6. | Article | PubMed

15. Okeson JP. Management of temporomandibular disorders and occlusion. 6th ed. St. Louis: CV Mosby. 2008.

16. Keshvad A and Winstanley RB. Comparison of the replicability of routinely used centric relation registration techniques. J Prosthodont. 2003; 12:90-101. | Article | PubMed

17. Williamson EH, Steinke RM, Morse PK and Swift TR. Centric relation: a comparison of muscle-determined position and operator guidance. $\mathrm{Am}$ J Orthod. 1980; 77:133-45. | Article | PubMed

18. Rosenblum RH and Huffman RW. Leaf gauge with consecutively numbered leaves. J Prosthet Dent. 1985; 54:652-4. | Article | PubMed

19. Carroll WJ, Woelfel JB and Huffman RW. Simple application of anterior jig or leaf gauge in routine clinical practice. J Prosthet Dent. 1988; 59:611-7. | Article | PubMed

20. Wood DP, Floreani KJ, Galil KA and Teteruck WR. The effect of incisal bite force on condylar seating. Angle Orthod. 1994; 64:53-61. | Article | PubMed

21. Alvarez MC, Turbino ML, Barros C, Pagnano VO and Bezzon OL. Comparative study of intermaxillary relationships of manual and swallowing methods. Braz Dent J. 2009; 20:78-83. | Article | PubMed

22. Shafagh I and Amirloo R. Replicability of chinpoint-guidance and anterior programmer for recording centric relation. J Prosthet Dent. 1979; 42:402-4. | Article | PubMed

23. McKee JR. Comparing condylar position repeatability for standardized versus nonstandardized methods of achieving centric relation. $J$ Prosthet Dent. 1997; 77:280-4. | Article | PubMed

24. Celar A, Freudenthaler J, Crismani A and Graf A. Guided and unguided mandibular reference positions in asymptomatic individuals. Orthod Craniofac Res. 2013; 16:28-35. | Article | PubMed

\section{Citation:}

Swenson AL, Oesterle LJ, Shellhart WC, Newman SM and Minick G. Condylar positions generated by five centric relation recording techniques. Oral Biol Dent. 2014; 2:8. http://dx.doi.org/10.7243/2053-5775-2-8 